\title{
Cooperative Operation Schedules of Energy Storage System and Demand Response Resources Considering Urban Railway Load Characteristic under a Time-of-Use Tariff
}

\author{
Hye Ji Kim² ${ }^{2}$ Hosung Jung ${ }^{1}$ Y Young Jun $\mathrm{Ko}^{2} \cdot$ Eun Su Chae ${ }^{2} \cdot$ Hyo Jin $\mathrm{Kim}^{2} \cdot$ II Seo Hwang ${ }^{2}$ Jae-Haeng Heo ${ }^{2}$. \\ Jong-young Park ${ }^{1}$ (i)
}

Received: 16 September 2020 / Revised: 6 December 2020 / Accepted: 22 January 2021 / Published online: 15 February 2021

(c) The Author(s) 2021

\begin{abstract}
This paper proposes an algorithm for the cooperative operation of air conditioning facilities and the energy storage system (ESS) in railway stations to minimize electricity. Unlike traditional load patterns, load patterns of an urban railway station can peak where energy charge rates are not high. Due to this possibility, if applying the traditional peak-reduction algorithm to railway loads, energy changes can increase, resulting in higher electricity bills. Therefore, it is required to develop a new method for minimizing the sum of capacity charges and energy charges, which is a non-linear problem. To get a feasible solution for this problem, we suggest an algorithm that optimizes the facility operation through two optimizations (primary and secondary). This method is applied to the air-quality change model for operating air conditioning facilities as demandresponse (DR) resources in railway stations. This algorithm makes it possible to estimate operable DR capacity every hour, rather than calculating the capacity of DR resources conservatively in advance. Finally, we perform a simulation for the application of the proposed method to the operation of DR resources and ESS together. The simulation shows that electricity bills become lowered, and the number of charging and discharging processes of ESS is also reduced.
\end{abstract}

Keywords Cooperative operation · Demand response · Time-of-use $\cdot$ Energy storage system $\cdot$ Urban railway load

Jong-young Park

jypark@krri.re.kr

Hye Ji Kim

khyeji@raonfriends.com

Hosung Jung

hsjung@krri.re.kr

Young Jun Ko

topko910@ raonfriends.com

Eun Su Chae

silverwater.chae@raonfriends.com

Hyo Jin Kim

hyogust@raonfriends.com

Il Seo Hwang

halluin@ raonfriends.com

Jae-Haeng Heo

hjh@ raonfriends.com

1 Electrification System Research Team, Korea Railroad Research Institute (KRRI), 176, Cheoldo Bangmulgwan-ro, Uiwang-si, Gyeonggi-do 16105, Korea

2 Energy Technologies and Economics, Raonfriends, Anyang-si, Gyeonggi-do, Korea

\section{Introduction}

As introducing the concept of the demand response (DR), the behavior of electricity consumers has changed from naively saving electricity to reduce electricity bills, to setting up a cost-saving strategy based on the price of electricity [1-4].

The basic strategy of DR is to reduce electricity bills by regulating the usage of electricity; i.e., one can reduce power consumption when the electricity price is high, and supplement it later when the price becomes lower. Research on applying this strategy to the operation of railway stations, especially for the possibility of using railway station loads as DR resources, has been vigorously conducted, where most studies focus on saving the total expense [5-7].

However, power consumption is directly related to the utility of consumers in a railway station. If power consumption is insufficient due to its high cost, the utility of consumers can decrease. In the case of railway stations, the level of particulates and temperature in a station are the key factors in determining customer satisfaction. In 
South Korea, for this purpose, it is recommended, by government regulation, that railway stations should lower the density of particulates below a certain level and maintain a comfortable temperature [8]. Therefore, station facilities should be operated in consideration of customer satisfaction and utility.

One of the ways to achieve both the saving electricity cost and customer utility is using energy storage system (ESS). ESS can support or replace power consumption of a railway station so that the air-conditioning and ventilation facilities in a station can be in operation as it was, while the power consumption pattern of the railway station can be managed according to electricity bills. Therefore, the Operation of ESS, can maximize saving electricity costs without degrading customer satisfaction [9-12].

However, this leads to excessive use of ESS. As ESS degradation/aging becomes an issue, it is required to operate ESS in consideration of the State of Health (SOH). Even though several studies considered the SOH of ESS, they cannot be a feasible solution. In reality, various factors such as type/capacity/installation environment affect the $\mathrm{SOH}$ of ESS, and it is impossible to consider all factors [13-17].

Accordingly, strategies of cooperative operation between DR and ESS are inevitable to alleviate those problems such as ESS degradation, reduction of customer's utility. This paper proposes a method for minimizing electricity bills as well as maintaining customer satisfaction with a cooperative operation between DR resources and ESS in railway stations. We also expect excessive ESS operation can be avoided.

When considering loads of railway station facilities as DR resources, an analysis of how much the loads can be used as DR resources should precede. Two methods can be suggested. Firstly, we can classify railway station loads based on interviews and analyze the historical data to estimate the amount of loads that can be used for the DR resources in advance $[18,19]$. With this method, it is relatively easy to estimate the DR capacity. This pre-calculation method, however, does not take into account the utility of railway users at the time when DR is active.

Alternatively, we can estimate the DR capacity by modeling the correlation between power consumption and user utility. This method can adjust the DR capacity to provide the desired utility level of a railway station $[9,18,20]$. However, it is difficult to estimate the DR capacity, compared to the pre-calculation method. It is because a large amount of data is required to be analyzed in order to fully understand the relation between power consumption and user utility. Even though there is another difficulty on modeling customer satisfaction, the merit of the modeling method is that the DR capacity for user utility can be calculated by taking into account the situation at the time of the DR; i.e., the amount of DR resources can be adjusted based on external conditions at a particular time.
In this study, customer satisfaction of railway users is assumed to be determined by temperature and particulate density in a railway station. They are strictly regulated by government regulations and are well controlled in South Korea. From multiple regression analysis, a regression equation, representing the relationship between power consumption and the factors (temperature and particulate density), is derived. As a result, the maximum DR capacity is computed, where temperature and particulate density are within the proper ranges.

Based on the regression result, we propose a method to minimize electricity bills for operating railway stations with the cooperative operation between DR resources and ESS. With this method, we expect to suppress possible customer complaints caused by excessive DR usage and to extend the life of ESS, implying a feasible solution for managing railway loads effectively and efficiently.

The paper is organized as follows. We present an overview of the characteristics of Time-Of-Use (TOU) fares, railway loads, and facilities in Chapter 2. The formalization of the proposed method and the results of applying it to actual data from South Korea subway stations are described in Chapter 3 and 4, respectively. We conclude in Chapter 5.

\section{Background}

\subsection{TOU(Time-of-Use) Pricing}

The TOU pricing is a rate plan that the unit price of electricity is divided into two or three sectors depending on power consumption by season or the time of day [9]. This plan consists of capacity charges and energy charges [9], and is designed to recover those charges in the power supply [14]. The TOU pricing belongs to a typical price-based DR program, balancing electricity usage by shifting demand from the peak time to off-peak times. Also, this pricing plan provides an incentive for consumers who reduce their power consumption [9]. In other words, this pricing plan allows power suppliers to compensate for the cost of generating energy and to induce to load patterns as the supplier intended.

Ideally, the unit price of electricity should be derived from load patterns at the time of use, where power configuration depends on such patterns and changes to handle demands. However, it is difficult to get real-time pricing based on varying load patterns because of realistic constraints. Electricity pricing is, therefore, divided into three sectors depending on the load level; peak load, mid-peak load, and off-peak load. This TOU structured rate is applied to industrial loads, where the price of each sector reflects the average cost fluctuation [21]. This tariff system strengthens demand management, contributing to stabilizing the power 
Table 1 An example of the industrial electricity TOU tariff in Korean

\begin{tabular}{lcccc}
\hline Time period & $\begin{array}{c}\text { Demand charge } \\
\text { rate }[\mathrm{KRW} / \mathrm{kW}]\end{array}$ & \multicolumn{3}{c}{ Energy charge rates [KRW/kWh] } \\
\cline { 3 - 5 } & & Summer & Spring/fall & Winter \\
\hline Off peak load & \multirow{2}{*}{7470} & 55.6 & 55.6 & 63 \\
Mid load & & 81.4 & 60.4 & 79.9 \\
Peak load & & 114.9 & 79.6 & 109.3 \\
\hline
\end{tabular}

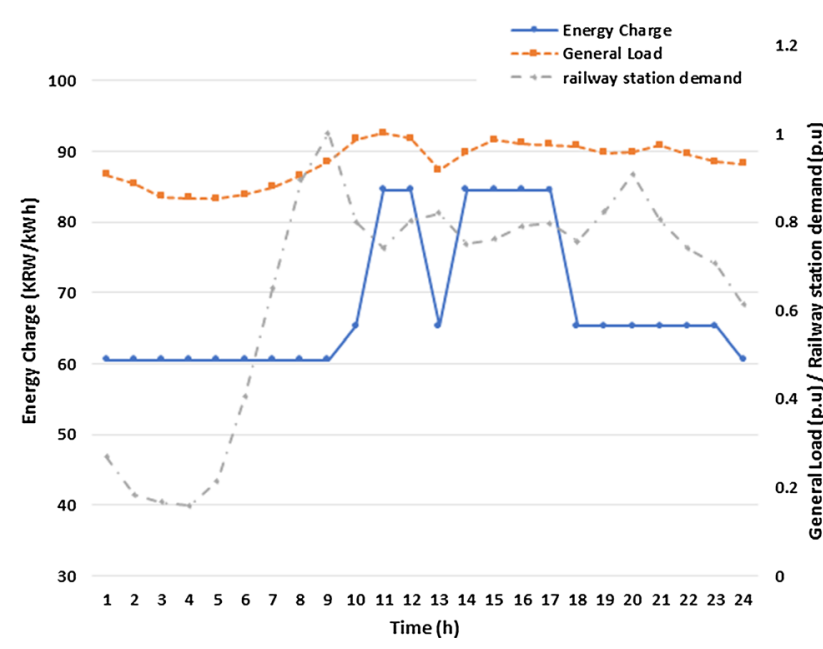

Fig. 1 Typical railway station load patterns and energy charges

supply [21]. Also, the system makes it possible to reduce new investment costs and to utilize resources optimally with demand management [21].

In South Korea, industrial electricity tariff induces DR to consumers with the TOU rate plan (see Table 1 as an example) [9]. The capacity charge is set to the highest amount of power demand during the previous 12 months when the peak load occurred $[9,22]$. The capacity charge can be reduced when the peak load decreases. The energy charge is generally designed to reflect variability between wholesale and retail markets [23].

\subsection{Characteristics of an Urban Railway Load}

Comparing railway station loads and general loads, the peak time is different from one another $[9,18]$. The general load peaks from 10 am to $5 \mathrm{pm}$ whereas the railway station load peaks at a rush hour ( 7 to 9 am and 7 to $9 \mathrm{pm}$ ). Figure 1 shows that the peak duration of railway station loads is shorter than that of general loads. Since railway station loads depend on the number of trains in operation, the amount of loads is significantly different at the peak and off-peak times. Therefore, unlike the general loads, it is possible to estimate the power demand at its peak relatively accurately by using the railway timetable [18].
The peak-time difference between railway station loads and general loads can be used for building a strategy for reducing power consumption [18]. In the case of general loads, the peak demand occurs during the peak time zone of TOU, so that the traditional strategy, shifting peak loads, can reduce both capacity and energy charges. In the case of railway station loads, the peak-load time is, however, different from the time of the highest energy charge. Due to this feature, the traditional strategy cannot be applied; this may increase energy charges. Therefore, the strategy for reducing energy consumption in railway loads should be established separately and deliberately in consideration of the characteristics of railway station demands [18].

Currently, electricity pricing for the Urban Railway Corporation in South Korea is the Class A High Voltage option II-type tariff (one of the TOU plans at industrial service). To minimize electricity bills, we need to minimize the sum of capacity and energy charges, rather than minimizing one of them. When the energy charge is forced to be lowest, the capacity charge can overwhelmingly increase due to excessive load in the off-peak period. In contrast, the lowest capacity charge does not ensure the lowest electricity bill, possibly due to a high energy charge $[9,18]$.

\subsection{Operational Facilities (DR resources and ESS)}

In railway load, the DR and ESS operations are the representative methods to reduce electricity bills [9]. In this paper, we propose the cooperative operation plan of ESS and DR resources in order to minimize electricity bills when operating railway stations.

The ESS operation doesn't mean that power consumption changes, but rather the power consumption of air-conditioning facilities remains the same. Instead, the ESS operation strategy aims to reduce the capacity charge by reducing the peak load and reduce the energy charge by utilizing the TOU pricing. The successful operation strategy makes it possible to shift demand loads in railway stations and, consequently, to lower electricity bills without degradation of satisfaction in railway services. However, this may lead to excessive ESS operation [9].

The introduction of DR for railway station facilities, especially for air conditioning and ventilation, affects customer satisfaction significantly. When an operator uses less power for air-conditioning and ventilation facilities, an electricity bill can be reduced. However, the quality of user utilities (air quality and temperature) will be significantly degraded. Therefore, railway station operators, who want to use air conditioning facilities as DR resources, should consider both saving electricity bill and fulfilling customer satisfaction at the same time [18]. 


\section{Algorithm}

As described earlier, railway station operators should consider reducing electricity bills while providing highquality services; if an operator focuses only on reducing electricity bills, it is hard to provide high-quality services to customers.

The important services for railway users are to provide a comfortable environment for customers as well as to make trains arrive or depart on time. Here, we focus on the former: providing the best environment for customers and lowering electricity bills. Note that the punctuality of trains is beyond the scope of this paper because it is not related to power consumption in railway stations.

In South Korea, there are government regulations on the level of temperature and particulates in railway stations. To follow the regulations, the operation of air-conditioning facilities is essential. Depending on operation strategies, power consumptions, peak loads, and, eventually, electricity bills can change.

Some railway stations have introduced ESS to minimize energy charges. ESS has been operated independently from air-conditioning facilities, which causes the excessive number of charge cycles of ESS. Due to such excessive cycles, the life of ESS is reduced. Also, the independent operation of ESS doesn't utilize controllable facilities, which may waste energy. This paper proposes an algorithm for the optimized cooperative operation of air-conditioning facilities and ESS. We expect that, with the proposed algorithm, electricity bills can be reduced and customer satisfaction is fulfilled.

\subsection{Structure of Algorithm}

The proposed algorithm minimizes electricity bills based on the TOU pricing in South Korea. As described in Chapter 2, electricity bills are divided into capacity and energy charges. Such characteristics of electricity bills leads to a non-linear problem that both capacity and energy charges should be considered simultaneously. This problem can be solved by the so-called Non-Linear Programming (NLP) process. To solve this complicated problem, we use two optimization steps: Quadratic Programming (primary) and Mixed-integer Programming (secondary).

Figure 2 shows a complete flowchart combining primary and secondary optimization. In the primary optimization, we obtain the optimized peak load, which is a minimum peak load when operating air-conditioning facilities. Then, the peak from the primary optimization is compared with the previous primary peaks obtained within current month, and then we select the highest peak. This is

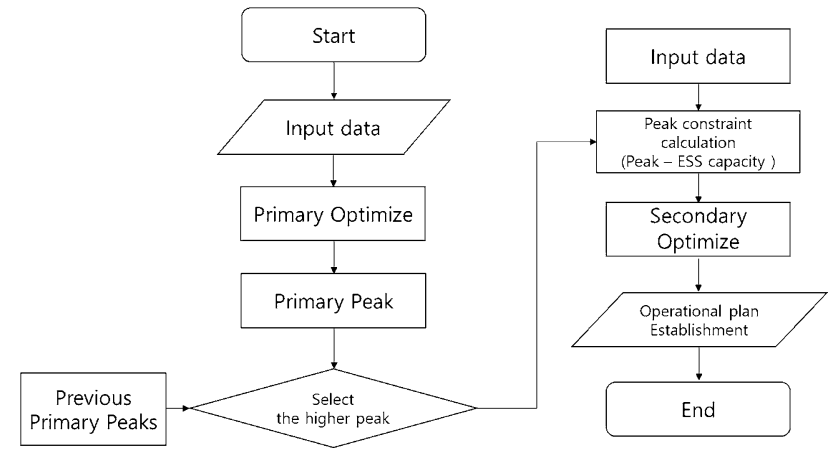

Fig. 2 Algorithm flow charts

because the capacity charge is determined by the highest peak within each calendar month. If a peak higher than the optimized peak of the target day has already appeared in the current month, there is no need to make an effort to reduce the peak of the target day. The selected peak is set to the peak constraint in the secondary optimization from which the energy charge is minimized.

\subsection{Primary Optimization}

In the primary optimization, the capacity charge is minimized without lowering consumer satisfaction. For this purpose, the primary optimization searches for the minimum peak load of railway station including air-conditioning facilities.

$\underset{\text { AHU }_{n, t} \text { BLower }}{n, t} \sum_{t=1}^{T}\left(A H U_{n, t}+\text { Blower }_{n, t}+\text { Dbase }_{n, t}\right)^{2}, \forall n \in N, t \in T$,

InTemp $^{\text {min }} \leq$ InTemp $_{n, t-1}+\Delta$ InTemp $_{n, t} \leq$ InTemp $^{\text {max }}, \forall n \in N, t \in T$,

InDust $^{\text {min }} \leq$ InDust $_{n, t-1}+\Delta$ InDust $_{n, t_{n, t}} \leq$ InDust $^{\max }, \forall n \in N, t \in T$,

Equation (1) indicates the objective function of optimization and aims to minimize the sum of squares of the total power used in loads in every single hour. $A H U_{n, t}$ and Blower $_{n, t}$ indicate the output of air-conditioning facilities and ventilation facilities, respectively. Dbase $_{n, t}$ indicates base demand of railway station loads excluding air-conditioning and ventilation facilities. $n$ and $N$ indicates the day of interest and the number of days in a month, respectively. $t$

indicates hours, and $T$ is equal to 24 , which is the total hours in a day.

Constraint Eq. (2) (Constraint Eq. (3)) implies that the sum of temperature (particulates) for the previous hour, InTemp $p_{n, t-1}\left(\right.$ InDust $\left._{n, t-1}\right)$, and its current change, $\Delta$ InTemp $_{n, t}\left(\Delta\right.$ InDust $\left._{n, t}\right)$ should be within the proper range. InTemp $^{\text {min }}\left(\right.$ InDust $\left.^{\text {min }}\right)$ and InTemp ${ }^{\max }\left(\right.$ InDust $\left.{ }^{\text {max }}\right)$ refer to the 
allowable minimum and maximum of the internal temperature (particulates), respectively.

\subsection{Primary Optimization}

\subsubsection{Correlation and Regression of Air Quality and Facilities}

The air quality of a railway station does not change when only ESS is operated, although electricity bills can change. It is because the charging and discharging processes of ESS don't affect the output of railway station facilities such as air-conditioning and ventilation facilities. In contrast, if the facilities are controlled, both electricity bills and air quality can change.

A change in the air quality of a railway station affects customer satisfaction. It is important to provide a certain level of service to customers when operating railway stations. In other words, operators should not reduce power consumption of the railway station facilities too much to save on electricity bills, as customer satisfaction can be significantly reduced.

To consider customer satisfaction, we derive the relationship between the power consumption of air-conditioning facilities and air quality. Then, we apply constraints for maintaining the air-quality level. In addition to the air-conditioning and ventilation facilities, air quality is affected by internal and external factors such as the number of passengers, and they are also considered in this study.

\section{Factors Affecting Air Quality}

In this paper, we model air quality in a station by taking into account controllable facilities and uncontrollable internal/ external factors. The controllable facilities are air-conditioners and ventilators (blowers). The uncontrollable factors include the number of passengers inside railway stations, the number of incoming trains, and outside environments (temperature and particulates). Note that it is impossible to consider all factors that affect air quality so that we assume that the effect of other factors on air quality is negligible.

First, Internal power facilities (Air conditioning facilities, blower). Air-conditioning facilities are equipped with particulate filters; the amount of particulates in railway stations is reduced while air-conditioners are in operation. On the contrary, ventilation facilities don't have such filters, so the internal and external particulate densities are synchronized while ventilators (or blowers) are in operation; i.e., if the external particulate density is lower than the density of particulates inside a railway station, the inside density will drop and vice versa. As for temperature control, air-conditioning facilities are set to operate at a certain temperature or above. In spring, the outside temperature is generally lower than the inside temperature of railway stations, so the operation of air-conditioning and ventilation facilities (e.g., circulation, supply, and exhaust) results in decreasing the inside temperature.

Second, Internal factors (passengers, incoming trains). Air quality is affected not only by the controllable facilities but also by uncontrollable various factors inside and outside railway stations. There are various internal factors such as the number of passengers, the number of incoming trains, humidity, station design, passenger movement patterns, and so on. In this paper, the number of passengers and incoming trains is considered due to the limitations of data acquisition. Incoming passengers and trains to a railway station bring external particulates into the station and raise the internal density of particulates. In the case of temperature in railway stations, temperature increases as the number of passengers increases, and decreases as the number of incoming trains increases.

Third, External factors (external temperature, external particulates). Air quality is influenced by external conditions as well; temperature and particulate density inside a railway station can be affected by outside values. This effect can be quantified by correlation analysis. We find a correlation between air quality and the external factors with data from railway stations and meteorological administration. Also, we perform a regression analysis with the same dataset to model air quality, considering time delay.

\section{Air Quality Modeling}

The following equations show the changes in temperature and particulates with multiple regression, taking into account time delay for each factor [16].

$$
\begin{aligned}
\Delta \text { InTemp }_{t}= & b_{T 0}+b_{T 1} \Delta \text { OutTemp }_{t-k T 1}+b_{T 2} A H U_{t-k T 2} \\
& +b_{T 3} \text { Blower }_{t-k T 3}+b_{T 4} \text { PAX }_{t-k T 4}+b_{T 5} \text { Train }_{t-k T 5} \\
\Delta \text { InDust }_{t}= & b_{D 0}+b_{D 1} \Delta \text { OutDust }_{t-k D 1}+b_{D 2} A H U_{t-k D 2} \\
& +b_{D 3} \text { Blower }_{t-k D 3}+b_{D 4} \text { PAX }_{t-k D 4}+b_{D 5} \text { Train }_{t-k D 5}
\end{aligned}
$$

$\Delta \operatorname{InTemp}(\Delta \operatorname{InDust})$ and $\Delta \operatorname{OutTemp}(\Delta$ OutDust $)$ are the changes in internal and external temperature (particulates), respectively. There are four variables affecting temperature and particulates: $A H U$ is the air-conditioning facilities output, Blower is the ventilator output, $P A X$ is the number of passengers, and Train is the number of incoming trains. $T$ and $D$ refer to temperature and dust (particulates), respectively. $b_{T 0} \sim b_{T 5}$ and $b_{D 0} \sim b_{D 5}$ are coefficients (or a constant 
coefficient), which are estimated from a regression analysis. $k T 1 \sim k T 5$ and $k D 1 \sim k D 5$ are time delay of variables. For the two equations, we perform a regression analysis with data from March of the spring season. Note that multiple regression coefficients and time delay are based on several assumptions because of the limitations of data acquisition and the limited number of variables that can be considered.

\section{Constraint on the Peak Load}

Peak $_{n}^{\text {DR }}=\max _{t}\left(A H U_{n, t}+\right.$ Blower $_{n, t}+$ Dbase $\left._{n, t}\right), \forall n \in N, t \in T$,

Equation (6) indicates the maximum load of a day after the primary optimization. As explained earlier, the capacity charge is determined by the highest load in a specified period. Due to the TOU pricing plan, if the previous peak load is higher than today peak load, the peak load is not renewed; conversely, if the today peak load is higher than the previous peak load, today peak load becomes the peak load. The peak load determined from this procedure becomes the peak constraint in the secondary optimization.

\subsection{Secondary Optimization}

The secondary optimization minimizes energy charges of a cooperative operation between DR resources and ESS.

$$
\begin{aligned}
& \min _{p_{n, t}} \sum_{t=1}^{T}\left(\rho_{n, t} \bullet p_{n, t}\right), \forall n \in N, t \in T, \\
& p_{n, t}= A H U_{n, t}+\text { Blower }_{n, t}+\text { Dbase }_{n, t} \\
&+ \text { ESS }_{n, t}^{+}-\text {ESS }_{n, t}^{-}, \forall n \in N, t \in T, \\
& \text { Peak }_{n}=\text { Peak }_{n}^{D R}-E^{\text {DS }}{ }^{\max }, \forall n \in N, t \in T, \\
& p_{n, t} \leq \text { Peak }_{n}, \forall n \in N, t \in T,
\end{aligned}
$$

InTemp $^{\text {min }} \leq$ InTemp $_{n, t-1}+\Delta$ InTemp $p_{n, t} \leq$ InTemp $^{\max }, \forall n \in N, t \in T$,

InDust $^{\text {min }} \leq$ InDust $_{n, t-1}+\Delta$ InDust $_{n, t_{n, t}} \leq$ InDust $^{\max }, \forall n \in N, t \in T$,

$E S S_{n, t}^{+} \leq E S S^{\max } \cdot \mu_{n, t}, \forall n \in N, t \in T$,

$E S S_{n, t}^{-} \leq E S S^{\max } \cdot\left(1-\mu_{n, t}\right), \forall n \in N, t \in T$,

$S o C^{\min } \leq S o C_{n, t} \leq S o C^{\max }, \forall n \in N, t \in T$,

$$
\begin{aligned}
& \mathrm{SoC}_{\text {init }}=\mathrm{SoC}_{\mathrm{n}, 96}=\frac{1}{5}\left(\mathrm{SoC}^{\max }-\mathrm{SoC}^{\mathrm{min}}\right), \forall n \in N, t \in T \text {, } \\
& \operatorname{SoC}_{n, t}=\operatorname{SoC}_{n, t-1}+\eta \cdot \operatorname{ESS}_{n, t}^{+} / \text {ESScap }-\frac{1}{\eta} \\
& \text { - } \text { SSS }_{n, t}^{-} / \text {ESScap }, \forall n \in N, t \in T \text {, }
\end{aligned}
$$

Equation (7) represents the objective function of secondary optimization. $\rho_{n, t}$ in Eq. (8) is hourly energy charges, and $p_{n, t}$ is the total load in railway stations including uncontrollable, controllable loads (air conditioning and ventilation facilities), and the power of charging and discharging ESS. The secondary optimization minimizes the sum of $\rho_{n, t}$ times $p_{n, t}$ which represents the total energy charges.

Peak $_{n}$ in Eq. (9) represents the maximum load obtained from the primary optimization minus the Power Conversion System (PCS) capacity of ESS. Constraint Eq. (10) is the maximum peak that the load of a railway station cannot exceed in each hour. Constraint Eqs. (11)-(12) are constraints for the temperature and particulates, which correspond to the constraint Eqs. (2)-(3) in the primary optimization. Constraint Eqs. (13)-(17) are related to ESS. Constraint Eqs. (13)-(14) are limits of the charging and discharging capacity.

$E S S^{\max }$ is the maximum charge/discharge capacity [W] of ESS, and $E S S_{n, t}^{+}\left(E S S_{n, t}^{-}\right)$represents charging (discharging) power $[\mathrm{kW}]$ at t-hours of $\mathrm{n}$-days. $\mu_{n, t}$ is an integer value ( 1 or 0$)$ : the charging state is 1 and the discharging state is 0 . For example, $\mu_{n, t}$ of 1 means that ESS is in the charging state at $\mathrm{t}$-hours of $\mathrm{n}$-days.

Constraint Eq. (15) is the State of Charge (SOC) constraint of ESS. SoC ${ }^{\min }$ and $S o C^{\max }$ are the minimum and maximum constraints [\%] of SOC, respectively. $S o C_{n, t}$ is the charging state [\%] of ESS at t-hours of n-days. Constraint Eq. (16) is a daily boundary condition, where the SOC of ESS maintains $20 \%$ of operational capacity $\left(S o C^{\max }-S o C^{\min }\right)$ at the beginning and end of a day. Constraint Eq. (17) represents the SOC constraint in consideration of the battery efficiency, $\eta$. ESScap is the PCS capacity of ESS, which is assumed to be equal to $E S S^{\max }$ in this paper.

\subsection{Summary and Contribution of the Proposed Algorithm}

In Chapter 3, we propose the operational algorithm that minimizes electricity bills of railway stations while maintaining customer satisfaction. We consider not only ESS but also DR resources. Air-conditioning and ventilation facilities are considered as DR resources in railway stations. 
It is important to consider maintaining customer satisfaction when DR resources are used. In the proposed algorithm, the air-quality change model is applied, where customer satisfaction is described with the output change of DR resources. This model uses a multiple regression equation of air-quality change, considering time delay based on actual data from railway stations. In this analysis, there are several assumptions in coefficients and time delay values due to the limitation of data acquisition. Since the proposed model takes into account current circumstances, railway stations can be operated within the maximum DR resources available at each hour. With this modeling method, it is possible to utilize DR resources optimally, compared to that of using the pre-calculated amount of DR resources. Also, this modeling method is expected to help to estimate the possible capacity of Fast/Flexible DR resources in the future.

\section{Simulation}

\subsection{Simulation Settings}

In this chapter, we perform a simulation, based on actual data, for confirming the effectiveness of the cooperative operation of DR resources and ESS in the context of managing loads and reducing electricity bills. For this simulation, we use one-hour unit data of railway stations of actual Korean local city on March 19th.

Also, we use data of external temperature and particulate density, which is adopted from the external institution $[24,25]$. The number of passengers and incoming trains is estimated, based on railway station data. Base demand, the base power consumption, refers to the total railway station loads excluding air-conditioning and ventilation facilities, whereas actual demand includes air-conditioning and ventilation facilities.

Table 2 shows the hypothetical ESS characteristics used in the secondary optimization. The capacity of this ESS is $20[\mathrm{~kW}]$. The maximum charging and discharging capacity of ESS is the PCS capacity. The SOC capacity is set to be in the range of $10[\%]$ to $90[\%]$, taking into account the battery life. The SOC capacity is set to have $20[\%]$ of the

Table 2 ESS characteristic

\begin{tabular}{ll}
\hline ESS parameters & Value \\
\hline PCS capacity [W] & 10,000 \\
Min. SOC capacity [Wh] & 2,000 \\
Max. SOC capacity [Wh] & 18,000 \\
Efficiency of ESS charging and discharging [\%] & 90 \\
\hline
\end{tabular}

operational capacity ( $S o C^{\max }-S o C^{\min }$ ) at the beginning and end of the day. The ESS efficiency is set to 90[\%].

\subsection{Simulation Results I-Constraint Dependence}

Table 3 shows the operational conditions of temperature and particulates for each case, based on actual data. Case 0 is derived from actual data on temperature and particulates of railway stations on March 19th. Case I-1 is set to have the same constraints as case 0 . Case I- 2 is when temperature and particulates are set to be more strictly constrained. Case I-3 is when temperature and particulates are set to be more loosely constrained. For each case in Table 3, we perform a simulation with its constraints.

Figures 3 and 4 show the changes of temperature and particulate density for each case on March 19th, respectively. In both figures, all cases satisfy the constraints of temperature and particulates.

Figure 5 shows the energy consumption for each case on March 19th. As shown in Table 4, the simulation results show that the peak energy, which occurs at 9 am, is reduced in all cases.

Table 3 Classification by temperature and particulate matter constraints for each case

\begin{tabular}{|c|c|c|c|c|}
\hline \multirow{2}{*}{$\begin{array}{l}\text { Simulation } \\
\text { case }\end{array}$} & \multirow{2}{*}{$\begin{array}{l}\text { Tem- } \\
\text { perature } \\
\text { constraint } \\
\text { Min. }\left[{ }^{\circ} \mathrm{C}\right]\end{array}$} & \multicolumn{3}{|c|}{ Particulate matter constraint } \\
\hline & & $\operatorname{Max} .\left[{ }^{\circ} \mathrm{C}\right]$ & Min. $\left[\mu \mathrm{g} / \mathrm{m}^{3}\right]$ & $\operatorname{Max} .\left[\mu \mathrm{g} / \mathrm{m}^{3}\right]$ \\
\hline Case 0 & 11.94 & 14.72 & 0 & 66.23 \\
\hline Case I-1 & 11.94 & 14.72 & 0 & 66.23 \\
\hline Case I-2 & 13 & 14 & 0 & 54 \\
\hline Case I-3 & 10 & 18 & 0 & 80 \\
\hline
\end{tabular}

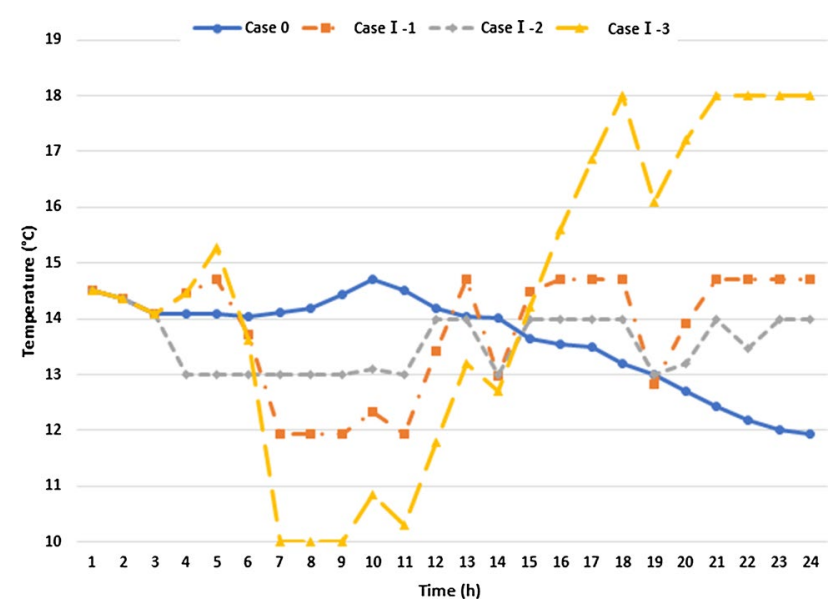

Fig. 3 Internal temperature of railway stations for each case 


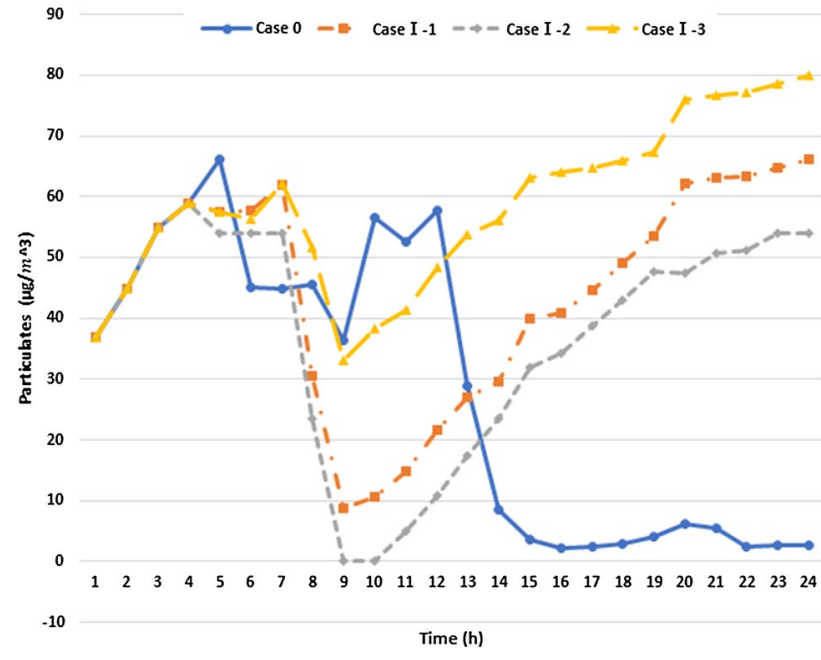

Fig. 4 Internal particulate matter of railway stations for each case

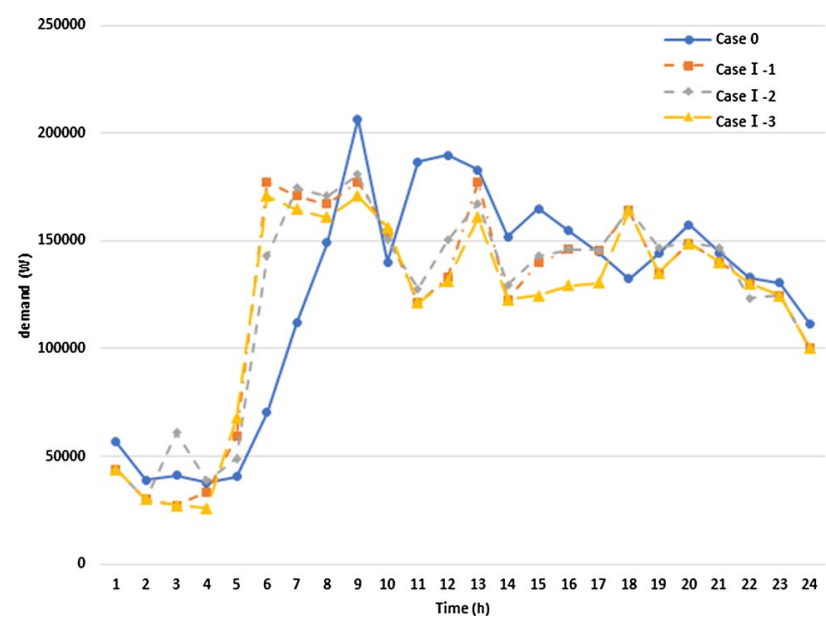

Fig. 5 Energy of railway stations for each case

Table 4 ESS characteristic

\begin{tabular}{lrrrc}
\hline & Case 0 & Case I-1 & Case I-2 & Case I-3 \\
\hline Peak $[\mathrm{kW}]$ & 196.37 & 177.22 & 180.86 & 170.9 \\
Energy $[\mathrm{kWh}]$ & 3022.12 & 2968.44 & 3005.49 & 2881.37 \\
\hline
\end{tabular}

Table 5 Electricity bill for each case
Table 4 shows the estimated electricity bill for each case. When calculating electricity bills, the aforementioned payment system, Industrial A, High voltage A, select 2, is selected. The capacity charge is 240.9 [KRW/kW], where a monthly rate $(7470[\mathrm{KRW} / \mathrm{kW}])$ is divided by (assumed) 31 days in order to get a daily rate. The total energy charge is calculated by summing up energy charges for each hour in a day. The energy charge for each hour is given by multiplying power consumption by its corresponding energy charge rate.

As in Table 5, the electricity bill of case 0 is 261,990 [KRW], which is higher than that of other cases. Case I-2 have lower capacity charges and energy charges than Case 0 . It implies that they can provide a more comfortable environment for customers as well as reduce electricity bills. In Case I-3, it is possible to reduce electricity bills significantly compared to the other cases. From this simulation study, we found that customer satisfaction and electricity bills depend on operational constraints (or conditions) of temperature and particulate density in railway stations. This result implies the importance of the consideration of these constraints when a railway station operator operates railway station facilities.

\subsection{Simulation Results II-Operational Facility Dependence}

Abbreviation and acronyms should be defined the first time they appear in the text even after the have already been defined in the abstract. Do not use abbreviations in the title unless they are unavoidable.

\subsubsection{Comparison of Load Patterns and Electricity Bills}

In this section, the optimization results for four operation strategies are compared: not operating both DR resources and ESS (Case0), operating only DR resources (Case II-1), operating only ESS (Case II-2), and a cooperating operation of DR resources and ESS (Case II-3). We perform a simulation for four cases (Table 6).

Figure 6 shows the change of load patterns in time for each case. The traditional method (Case 0 ) has a higher peak than that of the other methods (Case II-1, Case II-2, and Case II-3) and uses electricity when the energy charge is high. From this simulation, we found that the peak of energy

\begin{tabular}{lllll}
\hline Simulation case & $\begin{array}{l}\text { Capacity } \\
\text { charges } \\
{[\text { KRW] }}\end{array}$ & $\begin{array}{l}\text { Energy } \\
\text { charges } \\
{[\text { KRW] }}\end{array}$ & $\begin{array}{l}\text { Electricity bill (capacity } \\
\text { charges + energy charges) } \\
{[\text { KRW] }}\end{array}$ & $\begin{array}{l}\text { Electricity bill difference } \\
\text { (based on case 0) [KRW] }\end{array}$ \\
\hline Case 0 & 49,730 & 212,260 & 261,990 & 0 \\
Case I-1 & 42,705 & 204,626 & 247,332 & $-14,658$ \\
Case I-2 & 43,581 & 207,660 & 251,242 & $-10,748$ \\
Case I-3 & 41,181 & 198,121 & 239,303 & $-22,687$ \\
\hline
\end{tabular}


Table 6 Classification by DR resources and ESS operation state

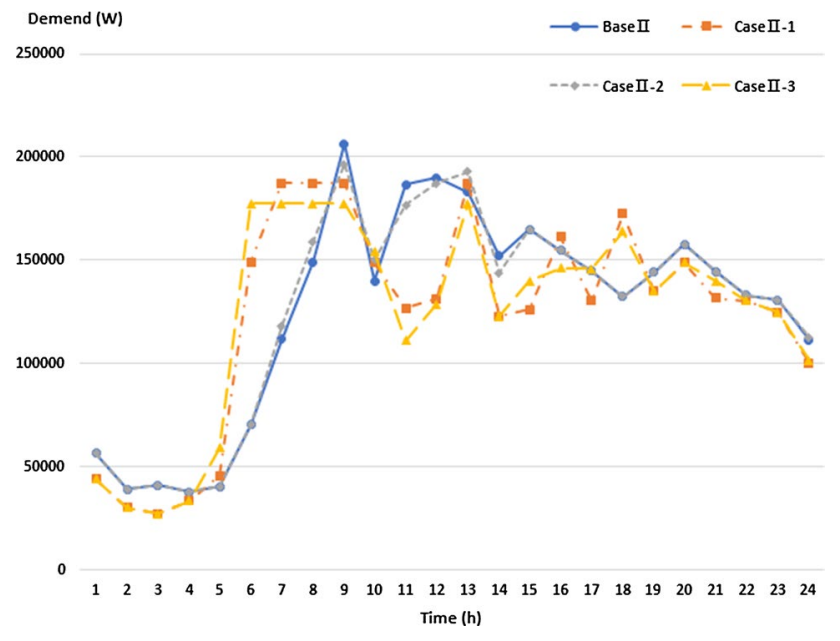

Fig. 6 Comparison load patterns for each case

Table 7 Peak and energy for each case

\begin{tabular}{lrrcc}
\hline & Case 0 & Case II-1 & Case II-2 & Case II-3 \\
\hline Peak [kW] & 206.37 & 187.23 & 196.38 & 177.23 \\
Energy [kWh] & 3022.12 & 2968.44 & 3029.3 & 2971.8 \\
\hline
\end{tabular}

consumption can be reduced in all cases, compared to the traditional method.

Table 7 shows the peak load and energy consumption for each case during a day. Case II-1 has the peak load and energy consumption lower than Case II-2. This implies that operating DR resources alone can provide the same utility as that of operating ESS alone with maintaining the level of customer satisfaction. Case II-3 has the lowest peak value, but the lowest energy consumption is achieved in Case II-1.
This result is based on the application of the TOU rate and ESS charging and discharging efficiency.

Table 8 shows an electricity bills for each case during a day. Case 0 has the highest electricity bill, implying that other methods (Case II-1, Case II-2, and Case II-3) can reduce electricity bills. Among the three cases, the lowest electricity bill is achieved in Case II-3. This is because the peak load is lowered so that the capacity charge is greatly reduced, though the energy charge of Case II-3 is slightly higher than that of Case II-1. More specifically, if DR resources and ESS are operated cooperatively, ESS makes it possible to use more resources at low-cost time sections, resulting in lowering the peak load.

\subsubsection{Comparison of ESS Operation Strategies}

This chapter describes how the ESS operation pattern of a railway station changes depending on whether or not DR resources are operated.

Figures 7 and 8 show the ESS operation schedule of operating ESS alone (Case II-2) and the cooperative operation between DR resources and ESS (Case II-3), respectively. Comparing the two figures, the number of ESS charging cycles of Case II-2 is significantly higher than that of Case II-3. This result implies that operating ESS alone to minimize electricity bills with fulfilling customer satisfaction can cause excessive use of ESS, which reduces the ESS life. Therefore, the cooperative operation of the DR resources and ESS is the best method in the context of not only minimizing electricity bills but also extending the ESS life by avoiding unnecessary charging cycles.

\section{Conclusion}

In this paper, we proposed an algorithm to save electricity bills for railway station operators, which maximizes the DR effect with the cooperative operation of air-conditioning facilities and ESS. In the case of railway station loads, unlike general loads, the peak time of power consumption doesn't usually occur at the peak section of energy charges in the TOU pricing. In other words, if the traditional method for reducing the peak load is applied in operating railway stations, the electricity bill is likely to increase due to higher

\begin{tabular}{llllll}
$\begin{array}{l}\text { Table } 8 \text { Electricity bill for each } \\
\text { case }\end{array}$ & Simulation case & $\begin{array}{l}\text { Capacity } \\
\text { charges } \\
{[\mathrm{KRW}]}\end{array}$ & $\begin{array}{l}\text { Energy } \\
\text { charges } \\
{[\mathrm{KRW}]}\end{array}$ & $\begin{array}{l}\text { Electricity bill (capacity } \\
\text { charges + energy charges) } \\
{[\mathrm{KRW}]}\end{array}$ & $\begin{array}{l}\text { Electricity bill difference } \\
\text { (based on case 0) [KRW] }\end{array}$ \\
\cline { 2 - 5 } & Case 0 & 49,730 & 212,260 & 261,990 & 0 \\
& Case II-1 & 45,115 & 204,410 & 249,526 & $-12,464$ \\
& Case II-2 & 47,320 & 212,296 & 259,616 & $-2,373$ \\
& Case II-3 & 42,705 & 204,485 & 247,191 & $-14,799$ \\
\hline
\end{tabular}




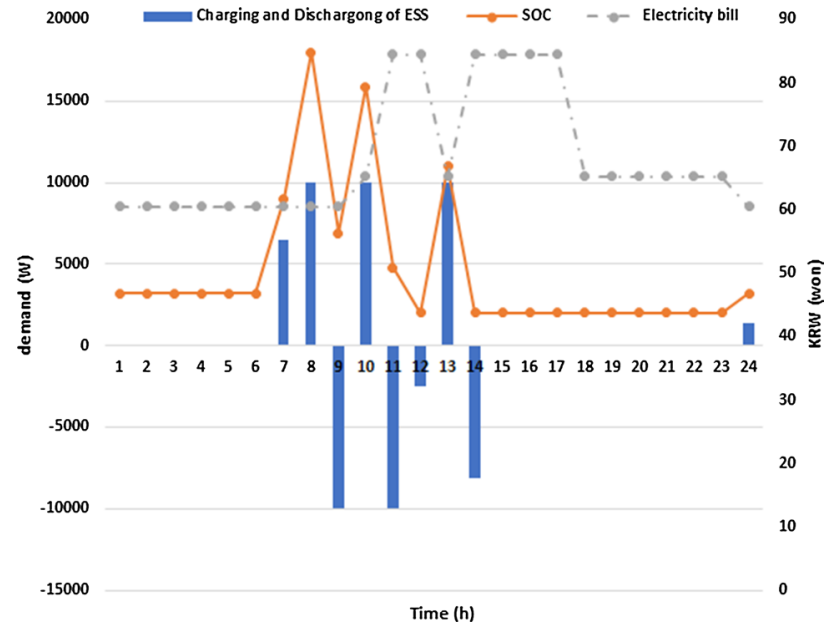

Fig. 7 Operational schedule of ESS for Case II-2

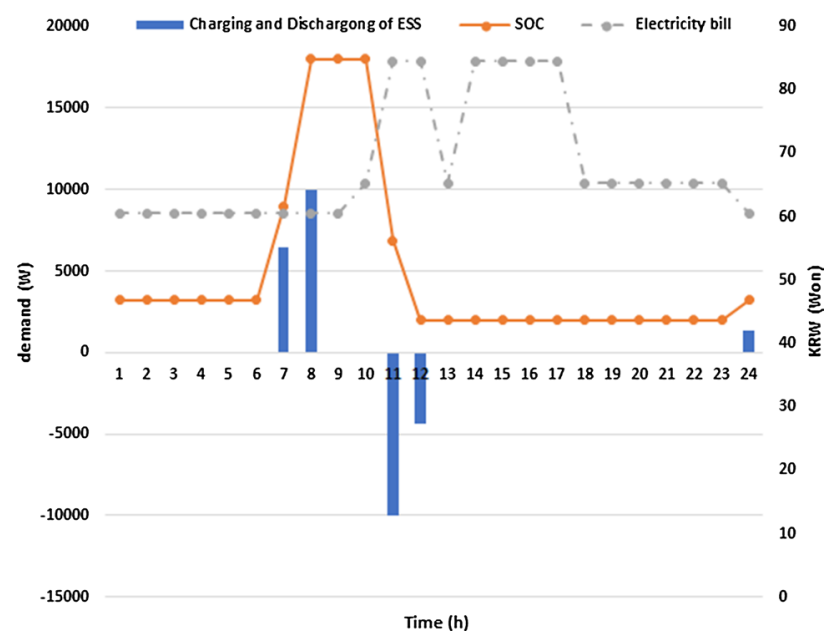

Fig. 8 Operational schedule of ESS for Case II-3

energy charges. Therefore, we proposed a new method that minimizes the sum of capacity and energy charges through primary and secondary optimizations.

For the operation of air-conditioning and ventilation facilities as DR resources, we applied a model, which considers the change in temperature and particulate density, to the proposed algorithm. In this analysis, internal and external factors, which affect temperature and particulate density, were taken into account.

From the simulation study, we found that an electricity bill is minimized when operating DR resources and ESS cooperatively with constraints. Based on the result, railway station operators can maintain the air quality of railway stations within the proper range, considering a trade-off between the cost of operation and air-quality constraints. Compared to operating DR resources or ESS independently, the cooperative operation of DR resources and ESS can maximize the cost-saving effect. Furthermore, the number of ESS charging cycles decreases when using DR resources and ESS together, compared to operating ESS alone.

Acknowledgements This research was supported by Korea Railroad Research Institute, Republic of Korea.

Open Access This article is licensed under a Creative Commons Attribution 4.0 International License, which permits use, sharing, adaptation, distribution and reproduction in any medium or format, as long as you give appropriate credit to the original author(s) and the source, provide a link to the Creative Commons licence, and indicate if changes were made. The images or other third party material in this article are included in the article's Creative Commons licence, unless indicated otherwise in a credit line to the material. If material is not included in the article's Creative Commons licence and your intended use is not permitted by statutory regulation or exceeds the permitted use, you will need to obtain permission directly from the copyright holder. To view a copy of this licence, visit http://creativecommons.org/licenses/by/4.0/.

\section{References}

1. Heo JH, Kim H, Shin S, Park JY, Kim H (2016) The optimal load curtailment of urban railway load. Trans Korean Inst Electr Eng 65(9):1610-1617

2. Eldali F, Hardy T, Corbin C, Pinney D, Javid M (2016) Cost-benefit analysis of demand response programs incorporated in open modeling framework. In: 2016 IEEE power and energy society general meeting (PESGM), pp 1-5

3. Bradley P, Leach M, Torriti J (2013) A review of the costs and benefits of demand response for electricity in the UK. Energy Policy 52:312-327

4. Mountain BR (2012) Reducing electricity costs through demand response in the national electricity market. Technical report

5. Kang DJ, Park SJ, Choi SJ, Han SJ (2011) A study on design of home energy management system to induce price responsive demand response to real time pricing of smart grid. J Korean Inst Illum Electr Install Eng 25(11):39-49

6. Setlhaolo D, Xia X, Zhang J (2014) Optimal scheduling of household appliances for demand response. Electr Power Syst Res 116:24-28

7. Yang H, Shen W, Yu Q, Liu J, Jiang Y, Ackom E, Dong ZY (2020) Coordinated demand response of rail transit load and energy storage system considering driving comfort. CSEE J Power Energy Syst 6(4):749-759

8. Namgung HK, Song JH, Kim SH, Kim HM, Kwon SB (2016) Characteristics of indoor air quality in the overground and underground railway stations. J Korea Acad Ind Cooper Soc 17(5):17-25

9. Heo JH, Shin S, Park JY, Kim H (2015) Study on the optimal operation of ESS considering urban railway load characteristic. Trans Korean Inst Electr Eng 64(10):1508-1516

10. Lee H, Lee H, Lee C, Jang G, Kim G (2010) Energy storage application strategy on DC electric railroad system using a novel railroad analysis algorithm. J Electr Eng Technol 5(2):228-238

11. Li N, Chen L, Low SH (2011) Optimal demand response based on utility maximization in power networks. In: 2011 IEEE power and energy society general meeting, pp 1-8

12. Yan L, Baek MK, Park JB, Park YG, Roh JH (2017) An optimal energy storage operation scheduling algorithm for a smart home considering life cost of energy storage system. J Electr Eng Technol 12(4):1369-1375 
13. Lei C, Meng J, Stroe DI, Peng J, Luo G, Teodorescu R (2020) Multi-objective optimization of data-driven model for lithiumion battery SOH estimation with short-term feature. IEEE Trans Power Electron 35:11855-11864

14. Haifeng D, Xuezhe W, Zechang S (2009) A new SOH prediction concept for the power lithium-ion battery used on HEVs. In: 2009 IEEE vehicle power and propulsion conference, pp 1649-1653

15. Li J, Adewuyi K, Lotfi N, Landers RG, Park J (2018) A single particle model with chemical/mechanical degradation physics for lithium ion battery state of health (SOH) estimation. Appl Energy 212:1178-1190

16. Choi Y, Kim H (2016) Optimal scheduling of energy storage system for self-sustainable base station operation considering battery wear-out cost. Energies 9(6):462

17. Abronzini U, Attaianese C, D’Arpino M, Di Monaco M, Tomasso G (2019) Cost minimization energy control including battery aging for multi-source ev charging station. Electronics 8(1):31

18. Park JY (2018) Analysis of electrical loads in the urban railway station by big data analysis. Trans Korean Inst Electr Eng 67(3):460-466

19. Shiljkut VM, Rajakovic NL (2015) Demand response capacity estimation in various supply areas. Energy 92:476-486

20. Ko W, Heo JH, Kang HK, Kim BK, Park JY (2020) Study on utilization of electric load in urban railway station to provide flexible demand response: case study in actual urban railway station. J Korean Soc Railw 23(3):243-251

21. Khalid A, Javaid N, Mateen A, Ilahi M, Saba T, Rehman A (2019) Enhanced time-of-use electricity price rate using game theory. Electronics 8(1):48

22. Jeon JH, Kim YK, Jung JS, Kim SD (2019) Feasibility analysis of tariff system for the promotion of energy storage systems (ESSs). New Renew Energy 15(3):69-76

23. Kim H, Heo JH, Park JY, Yoon YT (2017) Impact of battery energy storage system operation strategy on power system: an urban railway load case under a time-of-use tariff. Energies 10(1):68

24. Airkorea. (n.d.). Retrieved 28 Aug 2020, from https://www.airko rea.or.kr/web/last_amb_hour_data?pMENU_NO=123

25. Korea Meteorological Administration. (n.d.). Retrieved 28 Aug 2020, from https://data.kma.go.kr/data/grnd/selectAsosRltmList. do? $\mathrm{pgmNo}=36 \& \operatorname{tabNo}=2$

Publisher's Note Springer Nature remains neutral with regard to jurisdictional claims in published maps and institutional affiliations.

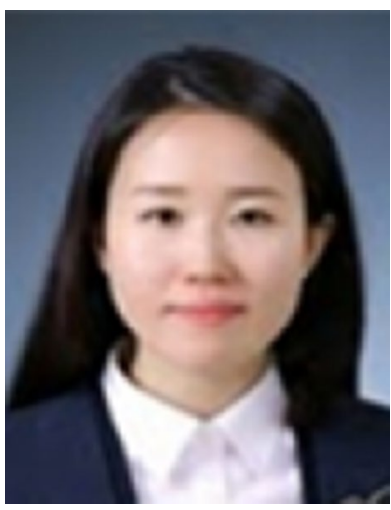

Hye Ji Kim She received her B.S. degree from Sung Kyun Kwan University, Gyenggi-do, Korea in 2012 and combined M.S./ Ph.D. degree from Seoul National University, Seoul, Korea, in 2020. Currently, she is a team leader at RaonFriends Co., Ltd., Korea from 2020. Her recent research interests include hosting capacity analysis, power system economics and urban railroad.

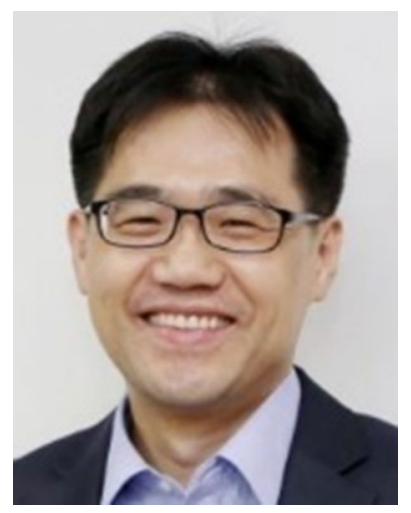

Hosung Jung He received his B.S., M.S., and Ph.D. degrees from Sungkyunkwan University, Korea, in 1995, 1998, and 2002, respectively. He is currently a Chief Researcher of Korea Railroad Research Institute (KRRI). His recent research interests include the protection of electric railway power system and energy efficient technology of power and railway system.

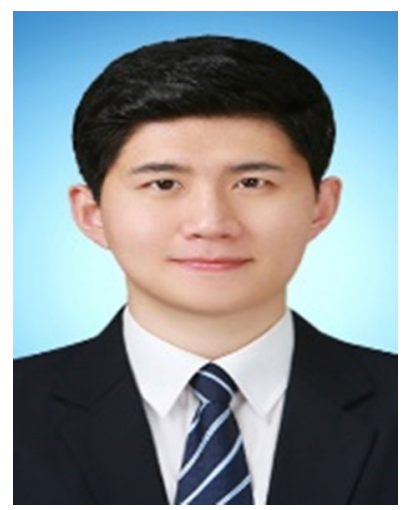

Young Jun Ko He received his B.S. and M.S. degree in electrical engineering from Korea Polytechnic University, Siheung, Korea in 2017 and 2020. Currently, he works at the RaonFriends Co. that is a consulting company for the power system and power system economics. His research field of interest includes economics analysis of power system and optimal operation of power systems.

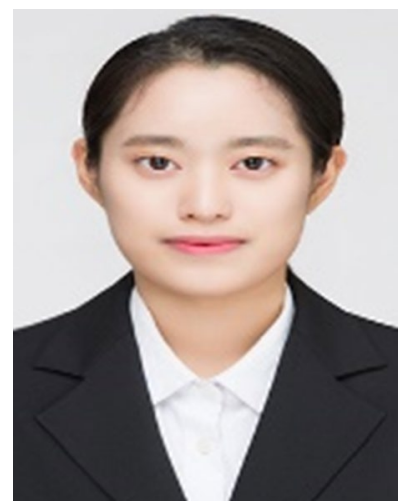

Eun Su Chae She received B.S. degree in electrical engineering from Korea Polytechnic University, Siheung, Korea in 2019. Currently, she is a researcher at Raon Friends Co., Ltd., Korea from 2019. Her recent research interests include the Power system, Hosting Capacity and AI.

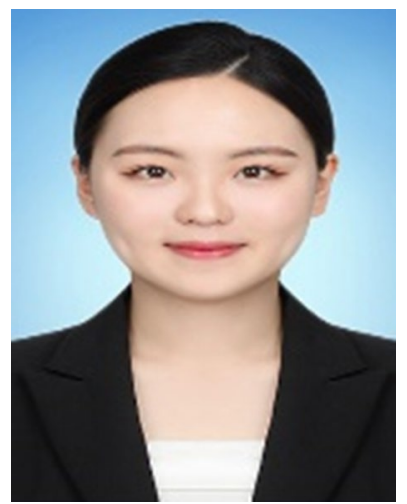

Hyo Jin Kim She received B.S. degree in electrical engineering from Korea Polytechnic University, Siheung, Korea in 2019. Currently, she is a researcher at Raon Friends Co., Ltd., Korea from 2019. Her recent research interests include the power system economics, electricity price plan analysis and Customer Baseline development. 


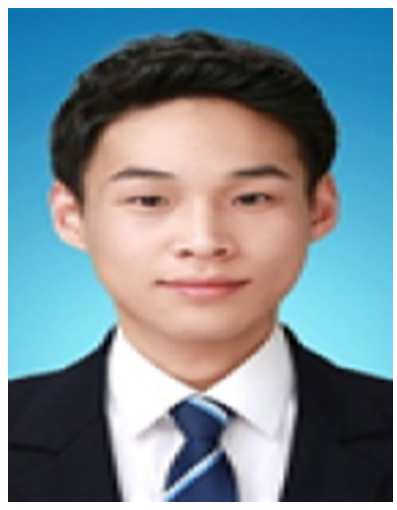

II Seo Hwang He received B.S. degree in electronic system engineering from Hanyang University, Ansan, Korea in 2017. Currently, he is a researcher at Raon Friends., Ltd., Korea from 2020. His recent research interests include Power system and Hosting Capacity.

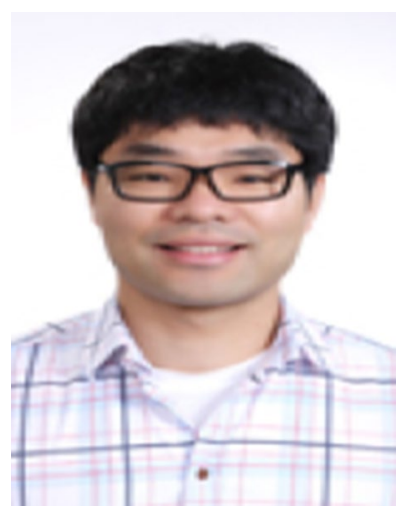

Jae-Haeng Heo He was born in Korea in 1978. He received his Ph.D. degree in Electrical Engineering from Seoul National University, Korea. Currently, he works at the RaonFriends Co. that is a consulting company for the power system and power system economics. His research field of interest includes power system reliability, equipment maintenance and urban railroad.

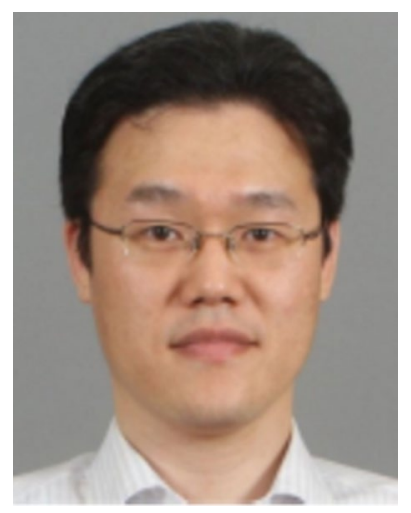

Jong-young Park He received his B.S., M.S., and Ph.D. degrees from Seoul National University, Seoul, Korea, in 1999, 2001, and 2007, respectively. He was a Senior Researcher at LSIS Co., Ltd., Korea from 2009 to 2013. Currently, he is a Senior Researcher at Korea Railroad Research Institute (KRRI). His recent research interests include the optimal operation of power systems in railway with the smart grid and AI technology. 